\title{
Editorial: Intact Forests
}

\author{
Tom D. Evans ${ }^{1 *}$, Alexandra C. Morel ${ }^{2}$, Yadvinder Malhi ${ }^{3}$ and James E. M. Watson ${ }^{4}$ \\ ${ }^{1}$ Global Conservation Program, Wildlife Conservation Society, Bronx, NY, United States, ${ }^{2}$ Department of Geography and \\ Environmental Science, University of Dundee, Dundee, United Kingdom, ${ }^{3}$ Environmental Change Institute, School of \\ Geography and Environment, University of Oxford, Oxford, United Kingdom, ${ }^{4}$ The School of Earth and Environmental \\ Sciences, University of Queensland, Brisbane, QLD, Australia
}

Keywords: ecological integrity, ecosystem services, forest degradation, climate resilience, nature-based solutions, area-based conservation, indigenous peoples, environmental policy

\section{Editorial on the Research Topic}

\section{Intact Forests}

\section{INTRODUCTION}

Earth's forests cover an area approximately equal to Africa and Europe's landmasses combined (Keenan et al., 2015) and play vital roles in the global carbon, water, and energy cycles. But there is growing evidence that intensive, industrialized human uses reduce forest ecological integrity and damage these and other processes. It is increasingly clear that the most intact forests, i.e., those free from significant human-induced degradation, tend to support the highest levels of many important ecosystem values and services (Watson et al., 2018). As such they require particular attention in policies and management.

This special issue of Frontiers in Forests and Global Change was inspired by the 2018 Oxford

OPEN ACCESS

Edited and reviewed by:

Mark Andrew Adams,

Swinburne University of

Technology, Australia

${ }^{*}$ Correspondence:

Tom D. Evans

tevans@wcs.org

Specialty section:

This article was submitted to Tropical Forests,

a section of the journal

Frontiers in Forests and Global

Change

Received: 05 August 2021

Accepted: 12 August 2021

Published: 06 September 2021

Citation:

Evans TD, Morel AC, Malhi Y and Watson JEM (2021) Editorial: Intact

Forests.

Front. For. Glob. Change 4:753786.

doi: 10.3389/ffgc.2021.753786
Conference on "Intact Forests in the Twenty First Century," which was held in part due to the increasing desire of the global conservation policy community to understand, map and conserve intact ecosystems. The issue contains fifteen papers which can inform global policy and practice in this critical area.

\section{CLARIFYING DEFINITIONS AND METRICS}

The term "intact forests" represent a special case of the broader concept of ecological integrity (or, equivalently, intactness); namely the degree to which the composition, structure and functions of an ecosystem are within their natural ranges of variability. This formed one of the foundational concepts of the 1992 Rio Declaration, but has proven difficult to operationalize beyond bottom-up, local approaches (Hansen et al., 2021). However, recent advances in remote sensing, big data and cloud computing have enabled new biome-wide or global metrics to be generated (Grantham et al., 2020; Hansen et al., 2020; Williams et al., 2020; Nicholson et al., 2021). Rapid further developments are anticipated, and these new tools have already helped to build the confidence of the global policy community that ecological integrity can be measured and monitored in practical ways. For example, an increasing number of countries are incorporating forest degradation data into their greenhouse gas reporting (Lee et al., 2018) and it seems likely that the Parties to the Convention on Biological Diversity (CBD) will include the maintenance of the integrity of forests and other natural ecosystems as a headline goal under the forthcoming Global Biodiversity Framework 2021-2050 (CBD, 2021).

Ecological integrity is a multi-dimensional concept (Nicholson et al., 2021) so scientists must be careful to define exactly which aspects of it they are measuring, and to recognize that different aspects of integrity may not be perfectly correlated. One key challenge is to specify the natural 
range of states where no integrity is considered to have been lost. In addition to data constraints, there are philosophical questions relating to what degree of human activity should be considered a part of the natural system and how ongoing changes in environmental conditions are treated (Ellis et al., 2021; Morel and Nogué). For example, Harvey et al. show that what ecosystem is considered 'intact' in the mountains of Guatemala depends in part on how far in the past the reference state is measured. A range of practical solutions exists (Hansen et al., 2021) as long as the issue is dealt with transparently, and as long as the sensitivity of results to the choice of approach is considered.

We note there is some debate over how best to qualify a forest as "intact" or "not intact," along a given dimension of integrity. Whilst binary categories are inherently attractive and can be potentially useful for policy design and communications (e.g., Potapov et al., 2017), it is important to recognize that they are usually simplifications of continuous gradients of variation. For example, Plumptre et al. found that even areas qualifying as Intact Forest Landscapes (IFLs) on structural grounds may not be wholly intact with respect to their vertebrate faunas, as some hunting-sensitive species are absent at some sites. A key insight here is that in the Anthropocene (Malhi, 2017) few, if any, forests still lie wholly within their natural ranges of variation on all dimensions (Malhi et al., 2014). Hence attempts to identify 'perfectly intact' forests are likely to be largely uninformative for policy and planning.

A more useful approach is to quantify the degree of integrity, and then to assess the levels of integrity below which particular environmental values are significantly reduced. This may in turn help to identify threshold levels for integrity which are relevant in a particular context. For example, Qie et al. (2017) found that average annual carbon sink values were consistently high across Bornean forest interiors but begin to drop off steeply within $450 \mathrm{~m}$ of a forest edge, indicating that below this particular threshold of structural integrity a significant change is observed in a key ecological function.

\section{VALUES ASSOCIATED WITH HIGH INTACTNESS}

A wide diversity of values and services tends to be found at higher levels in more intact forests of a given type. Biomass carbon stocks are a good example (Keith et al., 2009; Mackey et al., 2020), and forests and other ecosystems without a history of significant disturbance also collectively absorb around 30\% of anthropogenic carbon emissions annually (Friedlingstein et al., 2020). Two papers in this volume (Leverett et al.; Moomaw et al.) highlight the carbon values of intact North American forests, and also draw attention to the strong carbon sequestration services provided by older regrowth forests as their integrity returns toward more natural levels. Moreover, other climate regulatory services also tend to be higher in more intact forests, including moderation of local and regional air and land temperatures, and the return of moisture to the air through evapotranspiration (Baker and Spracklen).
Many aspects of biodiversity tend to be higher in more intact forests. For example, loss of ecological integrity tends to increase the numbers of species at elevated risk of extinction in an ecosystem (Betts et al., 2017; Donald et al., 2019) and to reduce or eliminate populations of many species (Haddad et al., 2015), including top predators and other species with large area requirements or particularly specialized niches. Hill et al. map variation in the natural (undisturbed) biodiversity importance of forests, and also estimate reductions in these forest species populations due to pressure from nearby human populations.

Many Indigenous Peoples' livelihoods and cultural security are underpinned by the integrity of the forest and other ecosystems within their territories and are at risk as degradation and clearance proceed (Garnett et al., 2018; Fa et al., 2020). There is often a reciprocal relationship between such communities and the integrity of their lands, since many have actively protected the lands they benefit from against destructive pressures originating elsewhere (Wells et al.).

The current global pandemic has put a spotlight on the sources of recent emerging infectious diseases, over $40 \%$ of which have been associated with transmission from wild animal species (Jones et al., 2008). Loss of integrity in natural systems, especially along tropical forest frontier zones, is believed to be a key factor driving rising rates of human-livestock-wildlife contact, and hence disease outbreaks, in recent decades (Dobson et al., 2020; Petrovan et al., 2021).

Due to methodological challenges, much remains to be learnt on the determinants of long-term ecosystem resilience, and on short-term resilience to conditions that ecosystems have not faced during the recent observational record (Morel and Nogué). Nonetheless, several key aspects of ecological resilience (including related concepts such as resistance) have been shown to be higher in intact forests and reduced following degradation (Thompson et al., 2009), including sensitivity to drought (Alencar et al., 2015) and vulnerability to fire (Nikonovas et al., 2020). For example, palaeoecological techniques show that intact Bornean mangroves appeared resilient over long periods to a regime of occasional fires, but experienced lasting and detrimental changes once fires, combined with multiple other pressures, exceeded some critical threshold of intensity following European colonization (Cole et al.).

\section{THREATS TO INTACT FORESTS}

Past pressures have already reduced the intactness of many forests such that only around $40 \%$ still have high ecological integrity (Grantham et al., 2020) with even less existing in blocks large enough to qualify as IFLs (Potapov et al., 2017). Declines are continuing, as shown by the $>9 \%$ decline in the global extent of IFLs during 2000-16 (Potapov et al., 2017 and updates thereto) ${ }^{1}$ Integrity is also in decline within these larger blocks (Benítez-López et al., 2019) and in smaller primary forest fragments outside them (Sabatini et al., 2020).

\footnotetext{
$\overline{{ }^{1} \text { http://intactforests.org/data.ifl.html }}$
} 
Many human activities are causing these declines, notably logging, infrastructure development, changes to natural fire and flood regimes, and fragmentation by expanding farms (Potapov et al., 2017; Scullion et al.) as well as less visible issues such as hunting, over-grazing, pollution, and invasive species. It is clear that these threats and their indirect drivers (economic, social, and demographic) will grow in the future. For example, Wells et al. summarize the vast and expanding industrial footprint of logging, hydropower, mining, and oil and gas across the North American boreal forests whilst Grantham et al. (2021) found that $20 \%$ of tropical IFLs are currently overlapped by licenses for exploration or extraction by the oil, gas and minerals sectors and Putz et al. (2012) famously noted that, aside from those in protected areas, most tropical forests have been or will be selectively logged. Over 25 million $\mathrm{km}$ of new roads will be built by 2050, many in currently intact areas (Laurance et al., 2014).

Detailed metrics allow the exact impacts of various processes to be explored at a range of scales-for example, first-cut selective logging in tropical forest typically leaves patches averaging almost $70 \%$ of the area allocated for harvesting undamaged, though this number may decline in subsequent cycles (Putz et al.). Osuri et al. highlight the differential impacts on faunal assemblages from hunting and from habitat disturbance, whilst Morgan et al. examine the fine-grain effects of certified logging on great ape habitats.

\section{SOLUTIONS: HALTING AND REVERSING THE DECLINE OF INTACT FORESTS}

Significant efforts are underway to halt both the deforestation and degradation of intact forests, and increasingly also to restore elements of integrity (e.g., rewilding). Proposed solutions are as diverse as the threats and drivers themselves (Scullion et al.). Wells et al. suggest a package of measures for the North American boreal zone whilst Moomaw et al. propose a refocusing on intact forest (which they term "proforestation") in the US context.

One group of solutions involves area-based conservation measures, which include state or private protected areas and a wide range of Indigenous- or community-led approaches, from protected areas to the broader-scale management of traditional territories. To be fully effective, area-based measures should be supported by legally recognized, multi-sectoral spatial plans. Few protected area systems currently meet the necessary thresholds for extent, representativeness or effectiveness due to a range of constraints (Maxwell et al., 2020). Resourcing, legal limitations and other factors also constrain Indigenous and communityled approaches from reaching their full potential scale or impact (RFN, 2021; Wells et al.). Furthermore, communities defending forests are being disproportionately targeted with violence and murder (Butt et al., 2019), making it urgent for the international community to recognize their contribution and intervene in these predominantly politically- and corporatedriven attacks.
A crucial complementary approach to area-based methods is to address the drivers of loss. For example, over the last decade there has been a swell of industry-led zero-deforestation supply chain commitments, but implementation is still lacking and many companies are yet to act (NYDF Assessment Partners, 2020). In addition, these efforts have been found to seldom target locations where the pressure on intact forests will be highest in future (Leggett and Lawrence, 2021). Kleinschroth et al. explore some of the challenges to using voluntary certification approaches to minimize the impacts of logging on intact forests. On deforestation, Haywood and Henriot argue that voluntary approaches are largely ineffective and that it is essential for the governments of forest countries to take the lead, setting and enforcing appropriate laws.

To be successful, both area-based and driver-based approaches require a range of enabling conditions across society, including an ambitious and well-designed policy framework with clear targets that make the retention of large areas of intact natural ecosystems a high priority at international and national levels across all sectors including climate, health, biodiversity, industry and rural development (Maron et al., 2018, 2020; Milner-Gulland et al., 2021). Other critical factors are the availability of credible evidence, high levels of public awareness and interest, sufficient financial resourcing, attention to human rights and stakeholder participation, and economic tools that promote more sustainable alternative forms of development (Díaz et al., 2020; Scullion et al.).

In conclusion, this special issue highlights the necessity to conserve intact forests for their unique role in maintaining a variety of ecological functions and values in the face of growing threats. Participants in the conference together wrote the Declaration on Intact Forests in the Twenty First Century ${ }^{2}$ which subsequently attracted support from a wide diversity of scientists, practitioners, and advocates. It is clear that if today's intact forests are to survive into the twenty second century, then globally coordinated action is very much needed, at all scales from individual sites and the struggles of environmental defenders through to over-arching UN conventions such as the CBD and UNFCCC.

\section{AUTHOR CONTRIBUTIONS}

TE, JW, AM, and YM conceptualized the manuscript. TE drafted the manuscript. JW and AM provided extensive edits. All authors contributed to the article and approved the submitted version.

\section{FUNDING}

TE was financially supported by UKAID from the UK government via the Forest Governance, Markets, and Climate Programme. YM was supported by the Frank Jackson Foundation. JW was partly supported by the Wildlife Conservation Society. The 2018 conference was supported by the John D. and Catherine T. MacArthur Foundation.

\footnotetext{
${ }^{2}$ https://www.eci.ox.ac.uk/if21/
} 


\section{REFERENCES}

Alencar, A. A., Brando, P. M., Asner, G. P., and Putz, F. E. (2015). Landscape fragmentation, severe drought, and the new Amazon forest fire regime. Ecol. Appl. 25, 1493-1505. doi: 10.1890/14-1528.1

Benítez-López, A., Santini, L., Schipper, A. M., Busana, M., and Huijbregts, M. A. (2019). Intact but empty forests? Patterns of huntinginduced mammal defaunation in the tropics. PloS Biol. 17:e3000247. doi: 10.1371 /journal.pbio.3000247

Betts, M. G., Wolf, C., Ripple, W. J., Phalan, B., Millers, K. A., Duarte, A., et al. (2017). Global forest loss disproportionately erodes biodiversity in intact landscapes. Nature 547, 441-444. doi: 10.1038/nature23285

Butt, N., Lambrick, F., Menton, M., and Renwick, A. (2019). The supply chain of violence. Nat. Sustain. 2, 742-747. doi: 10.1038/s41893-019$0349-4$

CBD (2021). First Draft of the Post-2020 Global Biodiversity Framework. CBD/WG2020/3/3. Available online at: https://www.cbd.int/doc/c/abb5/591f/ 2e46096d3f0330b08ce87a45/wg2020-03-03-en.pdf

Díaz, S., Zafra-Calvo, N., Purvis, A., Verburg, P. H., Obura, D., Leadley, P., et al. (2020). Set ambitious goals for biodiversity and sustainability. Science 370, 411-413. doi: 10.1126/science.abe1530

Dobson, A. P., Pimm, S. L., Hannah, L., Kaufman, L., Ahumada, J. A., Ando, A. W., et al. (2020). Ecology and economics for pandemic prevention. Science 369, 379-381. doi: 10.1126/science.abc3189

Donald, P., Arendarczyk, B., Spooner, F., and Buchanan, G. (2019). Loss of forest intactness elevates global extinction risk in birds. Anim. Conserv. 22, 341-347. doi: $10.1111 /$ acv. 12469

Ellis, E. C., Gauthier, N., Goldewijk, K. K., Bird, R. B., Boivin, N., Díaz, S., et al. (2021). People have shaped most of terrestrial nature for at least 12,000 years. Proc. Nat. Acad. Sci. 118:e2023483118. doi: 10.1073/pnas.2023483118

Fa, J. E., Watson, J. E., Leiper, I., Potapov, P., Evans, T. D., Burgess, N. D., et al. (2020). Importance of Indigenous Peoples' lands for the conservation of Intact Forest Landscapes. Front. Ecol. Environ. 18, 135-140. doi: 10.1002/fee. 2148

Friedlingstein, P., O'sullivan, M., Jones, M. W., Andrew, R. M., Hauck, J., Olsen, A., et al. (2020). Global carbon budget 2020. Earth Syst. Sci. Data 12, 3269-3340. doi: 10.5194/essd-12-32692020

Garnett, S. T., Burgess, N. D., Fa, J. E., Fernández-Llamazares, Á., Molnár, Z., Robinson, C. J., et al. (2018). A spatial overview of the global importance of Indigenous lands for conservation. Nat. Sustain. 1, 369-374. doi: 10.1038/s41893-018-0100-6

Grantham, H., Duncan, A., Evans, T., Jones, K., Beyer, H., Schuster, R., et al. (2020). Anthropogenic modification of forests means only $40 \%$ of remaining forests have high ecosystem integrity. Nat. Commun. 11, 1-10. doi: $10.1038 /$ s41467-020-19493-3

Grantham, H., Tibaldeschi, P., Izquierdo, P., Jones, K., Mo, K., Rainey, H., et al. (2021). The emerging threat of extractives sector to intact forest landscapes. Front. For. Glob. Change 4:72. doi: 10.3389/ffgc.2021.692338

Haddad, N. M., Brudvig, L. A., Clobert, J., Davies, K. F., Gonzalez, A., Holt, R. D., et al. (2015). Habitat fragmentation and its lasting impact on Earth's ecosystems. Sci. Adv. 1:e1500052. doi: 10.1126/sciadv.1500052

Hansen, A. J., Burns, P., Ervin, J., Goetz, S. J., Hansen, M., Venter, O., et al. (2020). A policy-driven framework for conserving the best of Earth's remaining moist tropical forests. Nat. Ecol. Evol. 4, 1377-1384. doi: 10.1038/s41559-0201274-7

Hansen, A. J., Noble, B. P., Veneros, J., East, A., Goetz, S. J., Supples, C., et al. (2021). Toward monitoring forest ecosystem integrity within the post-2020 Global Biodiversity Framework. Conserv. Lett. doi: 10.1111/conl.12822. [Epub ahead of print].

Jones, K. E., Patel, N. G., Levy, M. A., Storeygard, A., Balk, D., Gittleman, J. L., et al. (2008). Global trends in emerging infectious diseases. Nature 451, 990-993. doi: 10.1038 /nature06536

Keenan, R., Reams, G., Achard, F., de Freitas, J., Grainger, A., and Lindquist, E. (2015). Dynamics of global forest area: results from the FAO global forest resources assessment 2015. For. Ecol. Manage. 352, 9-20. doi: $10.1016 /$ j.foreco.2015.06.014
Keith, H., Mackey, B. G., and Lindenmayer, D. B. (2009). Re-evaluation of forest biomass carbon stocks and lessons from the world's most carbondense forests. Proc. Nat. Acad. Sci. 106, 11635-11640. doi: 10.1073/pnas.09019 70106

Laurance, W. F., Clements, G. R., Sloan, S., O'connell, C. S., Mueller, N. D., Goosem, M., et al. (2014). A global strategy for road building. Nature 513, 229-232. doi: 10.1038/nature13717

Lee, D., Skutsch, M., and Sandker, M. (2018). Challenges With Measurement and Accounting of the Plus in REDD+. San Francisco, CA: Climate and Land Use Alliance.

Leggett, M., and Lawrence, L. (2021). The Forest First Approach. New York, NY: Wildlife Conservation Society, AlphaBeta, Singapore.

Mackey, B., Kormos, C. F., Keith, H., Moomaw, W. R., Houghton, R. A., Mittermeier, R. A., et al. (2020). Understanding the importance of primary tropical forest protection as a mitigation strategy. Mitig. Adapt. Strateg. Glob. Change 25, 763-787. doi: 10.1007/s11027-019-09 891-4

Malhi, Y. (2017). The concept of the Anthropocene. Annu. Rev. Environ. Resour. 42, 77-104. doi: 10.1146/annurev-environ-102016-060854

Malhi, Y., Gardner, T. A., Goldsmith, G. R., Silman, M. R., and Zelazowski, P. (2014). Tropical forests in the Anthropocene. Annu. Rev. Environ. Resour. 39, 125-159. doi: 10.1146/annurev-environ-030713155141

Maron, M., Simmonds, J. S., and Watson, J. E. (2018). Bold nature retention targets are essential for the global environment agenda. Nat. Ecol. Evol. 2, 1194-1195. doi: 10.1038/s41559-018-0595-2

Maron, M., Simmonds, J. S., Watson, J. E., Sonter, L. J., Bennun, L., Griffiths, V. F., et al. (2020). Global no net loss of natural ecosystems. Nat. Ecol. Evol. 4, 46-49. doi: 10.1038/s41559-019-1067-z

Maxwell, S. L., Cazalis, V., Dudley, N., Hoffmann, M., Rodrigues, A. S. L., Stolton, S., et al. (2020). Area-based conservation in the twenty-first century. Nature 586, 217-227. doi: 10.1038/s41586-020-2773-z

Milner-Gulland, E., Addison, P., Arlidge, W. N., Baker, J., Booth, H., Brooks, T., et al. (2021). Four steps for the Earth: mainstreaming the post-2020 global biodiversity framework. One Earth 4, 75-87. doi: 10.1016/j.oneear.2020. 12.011

Nicholson, E., Watermeyer, K. E., Rowland, J. A., Sato, C. F., Stevenson, S. L., Andrade, A., et al. (2021). Scientific foundations for an ecosystem goal, milestones and indicators for the post-2020 global biodiversity framework. Nat. Ecol. Evol. [Epub ahead of print].

Nikonovas, T., Spessa, A., Doerr, S. H., Clay, G. D., and Mezbahuddin, S. (2020). Near-complete loss of fire-resistant primary tropical forest cover in Sumatra and Kalimantan. Commun. Earth Environ. 1, 1-8. doi: 10.1038/s,43247-02000069-4

NYDF Assessment Partners (2020). NYDF Progress Assessment Goal 2. Retrieved from: https://forestdeclaration.org/goals/goal-2

Petrovan, S. O., Aldridge, D. C., Bartlett, H., Bladon, A. J., Booth, H., Broad, S., et al. (2021). Post COVID-19: a solution scan of options for preventing future zoonotic epidemics. Biol. Rev. doi: 10.1111/brv.12774. [Epub ahead of print].

Potapov, P., Hansen, M. C., Laestadius, L., Turubanova, S., Yaroshenko, A., Thies, C., et al. (2017). The last frontiers of wilderness: tracking loss of intact forest landscapes from 2000 to 2013. Sci. Adv. 3:e1600821. doi: 10.1126/sciadv.1600821

Putz, F. E., Zuidema, P. A., Synnott, T., Peña-Claros, M., Pinard, M. A., Sheil, D., et al. (2012). Sustaining conservation values in selectively logged tropical forests: the attained and the attainable. Conserv. Lett. 5, 296-303. doi: 10.1111/j.1755-263X.2012.00242.x

Qie, L., Lewis, S. L., Sullivan, M. J., Lopez-Gonzalez, G., Pickavance, G. C., Sunderland, T., et al. (2017). Long-term carbon sink in Borneo's forests halted by drought and vulnerable to edge effects. Nat. Commun. 8, 1-11. doi: 10.1038/s41467-017-01997-0

RFN (2021). Falling Short. Donor Funding for Indigenous Peoples and Local Communities to Secure Tenure Rights and Manage Forests in Tropical Countries (2011-2020). Rainforest Foundation Norway, Oslo.

Sabatini, F. M., Keeton, W. S., Lindner, M., Svoboda, M., Verkerk, P. J., Bauhus, J., et al. (2020). Protection gaps and restoration opportunities for primary forests in Europe. Divers. Distrib. 26, 1646-1662. doi: 10.1111/ddi.13158 
Thompson, I., Mackey, B., McNulty, S., and Mosseler, A. (2009). Forest Resilience, Biodiversity, and Climate Change. Secretariat of the Convention on Biological Diversity, Montreal, QC. Technical Series no. 43, 1-67.

Watson, J. E., Evans, T., Venter, O., Williams, B., Tulloch, A., Stewart, C., et al. (2018). The exceptional value of intact forest ecosystems. Nat. Ecol. Evol. 2, 599-610. doi: 10.1038/s41559-018-0490-x

Williams, B. A., Venter, O., Allan, J. R., Atkinson, S. C., Rehbein, J. A., Ward, M., et al. (2020). Change in terrestrial human footprint drives continued loss of intact ecosystems. One Earth 3, 371-382. doi: 10.1016/j.oneear.2020. 08.009

Conflict of Interest: The authors declare that the research was conducted in the absence of any commercial or financial relationships that could be construed as a potential conflict of interest.
Publisher's Note: All claims expressed in this article are solely those of the authors and do not necessarily represent those of their affiliated organizations, or those of the publisher, the editors and the reviewers. Any product that may be evaluated in this article, or claim that may be made by its manufacturer, is not guaranteed or endorsed by the publisher.

Copyright $\odot 2021$ Evans, Morel, Malhi and Watson. This is an open-access article distributed under the terms of the Creative Commons Attribution License (CC BY). The use, distribution or reproduction in other forums is permitted, provided the original author(s) and the copyright owner(s) are credited and that the original publication in this journal is cited, in accordance with accepted academic practice. No use, distribution or reproduction is permitted which does not comply with these terms. 